\title{
Society's Request for Conversion Therapy: Is It Effective and Ethical to be Done?
}

\author{
Stefany Valentia ${ }^{1, *}$ Elizabeth Kristi Poerwandari ${ }^{2}$
}

\author{
${ }^{I}$ Clinical Psychology Department Faculty of Psychology University of Indonesia \\ ${ }^{2}$ Clinical Psychology Department Faculty of Psychology University of Indonesia \\ *Corresponding author. Email: stefany.valentia@gmail.com
}

\begin{abstract}
As a conservative country, Indonesia is one of the countries that is still struggling to accept homosexuality. General view of sexual identity and sexual orientation is fixated on binary concept, where sexual identity is considered same as gender. Despite homosexuality being no longer categorized as mental disorder in Diagnostic and Statistical Manual of Mental Disorder (DSM), society still pressures the non-conforming sexual groups to change their identity and sexual orientation using conversion therapy. Conversion therapy includes any kind of therapy that intends to alter one's sexual orientation, from homosexuality to heterosexuality. This research aims to examine the effectiveness and ethical issues of conversion therapy. Based on narrative literature study, it can be concluded that conversion therapy is not effective in changing one's sexual orientation, especially when the request for conversion comes from others. Conversion therapy can lead to self-hatred, shame, depression, and sexual dysfunction, especially in those who are forced to undergo the therapy by others. However, if the urge for therapy comes from one's personal desire, the therapist is obliged to have further discussion with the client and provide a better understanding about conversion therapy. This research also discusses other alternatives which can be given to those who seek 'recovery.
\end{abstract}

Keywords: Conversion Therapy, Ethical Issue, Homosexual, LGBT

\section{INTRODUCTION}

On 7th December 2018 [1], Australia Today published an article titled "Exorcisms are Being Used as Gay Conversion Therapy in Indonesia". As stated in the article, some people in Indonesia still see homosexuality as a result of demon possession. Thus, exorcism is necessary to evict demons from those with homosexuality. One of the mayors mentioned that homosexuality needs to be opposed as it destructs nation's morality. Another recent news published on 3rd June 2019 [2] with the headline "BKKBN Sebut LGBT Musuh Pembangunan" or "Family Planning Board calls LGBT a 'sexual disease', enemy of development". These news undeniably keep on occurring in Indonesia which indicates that there seems to be a false mindset and sexual identity discrimination.

Sexual minority is a term used to portray stigmatized sexual identity and sexual orientation that receive injustice behaviors among society [3]. Although sexual identity concept vary, it is often seen as a binary concept where sexual identity equals gender. The number of campaigns defending the rights of sexual minorities around the world has increased and various countries have legalized same-sex marriage, yet heterosexuality is still considered as the sole acceptable sexual orientation in society. Indonesia is a conservative country where religious beliefs are being held strongly. In Indonesia, homosexuals still conceal their sexual identity because it is less acceptable [4].

Parents are often the ones who actively seek ways to alter sexual orientation after finding out their child's homosexuality. A normative mindset lead parents to think that homosexuality is a mental disorder, thus can be cured with certain ways. Parents are often ashamed and afraid of society's judgment towards their child's sexual orientation. There might also be denial, guilt, sadness, anger and regret as well, regarding their child's sexual identity [5].

Homosexuality was once considered as a mental disorder and classified in the first edition of Diagnostic and Statistical Manual of Mental Disorder in 1952 as "sociopath personality disorder" (DSM; American 
Psychological Association). In DSM-II, published in 1968, homosexuality was reclassified as a "sexual deviation". DSM-III further modified this to "egodystonic homosexuality". However, some gay and lesbian activists rejected the pathological model of homosexuality and brought modern sex research theories by sexologists to the attention of APA. They based their protest on the Kinsey reports, who found that homosexuality was more common in the general population than it was generally believed [6]. Not until 1971 the diagnosis was being reviewed by Spitzer who was one of APA subcommittee. In the seventh printing of DSM-II second edition (APA, 1974), homosexuality is no longer listed as a mental disorder. This decision has been made by APA because of the subjective distress and impairment in functioning characteristics of mental disorders that do not fit with individuals with homosexual orientation [7].

Other than that, homosexuality was also considered as a defiant from religion and state laws. Various kinds of interventions are applied to cure homosexuality as it is frequently associated with criminal behaviors [8]. Intervention that intend to alter one's sexual orientation is also known as conversion therapy, reorientation therapy, or reparative therapy. A more common term is sexual orientation change efforts (SOCE) which is defined as any kind of effort performed to change one's sexual orientation [9]. However, this research will use the term conversion therapy to refer to intervention performed to alter one's sexual orientation and sexual identity.

Conversion therapy is any kind of therapy including individual speech therapy, behavioral therapy, or group therapy with the purpose to redirect one's sexual orientation from homosexual to heterosexual. Conversion therapy aims to get the individuals to stop identifying themselves as homosexuals, performing same-sex sexual activities, being sexually attracted to same-sex individuals, and being involved with individuals who are sexually attracted to same-sex individual [10]. There are various types of conversion therapy. Initially, religious institution often used aversion technique to cure homosexuality. They would electrocute the hands and genitals of those with homosexuality while showing them homosexual related materials [22]. As reviewed in [8], other ways include imagining homoerotic situations and associating them with an unpleasant feeling such as pain; reconditioning orgasm by masturbating to homosexual materials and replacing them with heterosexual materials when they are close to orgasm; also others that use aversion principle, such as convert sensitization technique and sexual surrogate or diversion.

In the study performed [10], several gay men explain their experiences while undergoing exorcism to evict homosexual demon living inside them as a form of conversion therapy. Some men with gay sexual identity were interviewed about their own experiences with conversion therapy [11]. As a part of the therapy, the participants were asked to spend time with heterosexual men, participating in sporty activities, such as rugby and golf. In addition, they were also asked not to participate in any activities with other homosexual men and to establish romantic relationships with women instead.

Throughout its development over years, homosexuality is no longer considered as a mental disorder and has been taken out of DSM since 1974 [12]. Whereas transgender is still listed under sexual disorder in DSM-V [13] with the term gender dysphoria. This fact implies that homosexuality is not a disease and it does not need to be cured. Hence, any particular intervention or therapy is unnecessary. However, it is undeniable to acknowledge that such practices still exist among the society, especially among some Indonesian people. Therefore, this article aims to further discuss about conversion therapy, especially to which extent it can be considered effective.

\section{RESEARCH QUESTION}

Based on the explanation above, the research questions in this literature review are: (1) How effective is the implementation of conversion therapy among homosexuals? (2) How is the ethical issues concerning conversion therapy?

\section{RESEARCH METHODS}

This design used in this paper is narrative literature review of research articles related to the underlying topic. The researchers collected data from electronic journals accessed from online database, consisting of ProQuest, Sage Publication, Science Direct, Taylor and Francis, and SpringerLink. The articles used in this research were obtained from international journals, such as journal of gay and lesbian mental health, journal of gay and lesbian psychotherapy, journal of homosexuality, journal of clinical psychology, and others.

The keywords utilized in the searches are homosexuality, LGBT, and conversion therapy. While the period of the targeted studies are within the last 10 years from 2009-2019, to ensure that the articles reviewed are up to date. To be included in the analysis, a text needed to (a) have been published in the past 10 years; (b) be in English; (c) provide results from a survey, qualitative study, or literature review; and (d) capture some aspect related to conversion therapy, such as the effectiveness and implication of the said therapy. Further information on articles are provided in Table 1. 


\section{DISCUSSION}

\subsection{Sexuality}

Sexuality is a broad concept involving sexual feelings, thoughts, attractions, fantasies, biological, erotic, physical, emotional, social, or spiritual feelings and behaviors. Sexuality is often associated with but not limited to one's sexual orientation [3]. The biological aspects of sexuality are related to the reproductive functions of individuals, while the emotional aspects of sexuality are related to affection and romanticism towards other individuals. Social aspects are related to how the social environment influences individual sexuality [14]. Therefore, it can be concluded that sexuality is not only about sexual behavior. Sexual orientation is one part of sexuality that affects one's sexual interests. LGBT stands for Lesbian, Gay, Bisexual, and Transgender. This term has been used since the 1990s, replacing the phrase 'gay'. Lesbian is a general term used for women who direct their sexual orientation choices to fellow women. Gay is the term referring to men who have sexual tendencies to fellow men. Bisexual is the term for an attraction towards samesex and opposite-sex. While transgender is a person whose way of behaving or appearance is not in accordance with gender roles in general, even they can change their sex, such as men change their sex into women or vice versa. There is a difference between homosexual behavior and homosexual identity. Homosexual behavior is the action of having sex with someone of the same sex, while homosexual identity is seeing oneself as a homosexual. Often time, the term homosexual is used to define all of the above, including bisexual [15].

Sexual orientation is described as individual's attraction to certain sex, including physical attraction, emotional attraction, also sexual behaviors which may or may not remain the same throughout a period of time. Whereas sexual identity can be classified into asexual, the absence of sexual attraction; bisexual, being sexually attracted to both men and women; gay, a man's attraction to other men; lesbian, a woman's attraction to other women; queer, not identifying oneself with any gender identities in particular; and questioning, doubting one's gender identity [3].

In a classical study [6], it is stated that human sexuality is a continuum rather than polar opposite. Sexual orientation ranges from exclusively heterosexual to exclusively homosexual. Someone who is exclusively heterosexual make no contact and psychic responses which results in erotic arousal to individuals of their own sex. While someone who is exclusively homosexual is involved in physical or psychic reactions of individuals of the same sex. In between the continuum are predominantly heterosexual, predominantly heterosexual but more than incidentally homosexual, equally heterosexual and homosexual, and predominantly homosexual but more than incidentally heterosexual. Those who fall in between the continuum might have some interest in homosexual stimuli, but still maintain their heterosexual activity, and vice versa.

Homosexuality in Indonesia in general is still considered taboo by society and government. Public discussions about homosexuality are very limited and rarely discussed openly. When discussing basic rights of citizens, the LGBT community find many difficulties and social clashes. Moreover, if we look at the customs in Indonesia and the people who hold fast to conservative religious doctrine, LGBT people are often regarded as a destroyer of religion and the cause of the of God's punishment, if they continue to voice their basic rights of the LGBT community.

Up until now, what underlies one's sexual identity still remains unknown. However, there are several studies that discuss how one's sexual identity is formed. References [16] discussed several possible factors which contribute to sexual identity formation, such as fetus development, brain anatomy and function, genetic behaviors, environmental factors, also childhood and teenage experiences. In studies about fetus development, it is hypothesized that homosexuality among men is caused by lack of testosterone on prenatal phase. This condition is triggered by mother's high stress level which then decreases the child's masculinity in sexual behavior and brain morphology. However, this statement remains inconclusive because no other study can support it [16].

Study about brain anatomy and function proposes a hypothesis that there are differences in size of certain brain area and the different activated neural circuit while looking at sexually arousing visual images, such as ventral striatum and centromedian thalamus among homosexual and heterosexual individuals [17]. Whereas the left caudate, left angular gyrus, and right pallidum activation is exclusive to homosexuals [18]. The term 'functional endophenotype' then occurs in a study about brain function, which originated from the discovery of different activation of reward-related brain area, in relation to sexual partner preferences. On the other hand, studies about genetic behavior discovered that the chance of obtaining homosexuality among monozygotic twins is $52 \%, 22 \%$ among dizygotic twins, and $11 \%$ among adopted siblings [16].

Furthermore, studies about environmental factors and childhood experiences found that an interaction between genetic and external factors contribute to one's sexual identity formation. While some homosexual individuals reported that they have been aware of their same-sex attraction since childhood, other studies assume how being adopted by homosexual parents may affect one's 
sexual identity development. However, these studies face a dead end as the majority of homosexual individuals have heterosexual parents, making it hard to point the main factor that affect one's sexual identity formation [16]. In conclusion, being attracted to any sex in particular is neither something beyond one's control nor is it caused by any error or deficiency during one's development. Therefore, this discussion further confirms the questionable effectiveness of conversion therapy.

\subsection{Effectiveness of Conversion Therapy}

One of the few studies that claims the success of conversion therapy is that by Spitzer [19]. This research was conducted to 200 individuals, where the participants succeed in maintaining their heterosexual identity for years. Spitzer arrived at the conclusion that sexual orientation change was possible, not only in behavior, but also identity, attraction, and content of fantasies. On top of that, Spitzer notified that participants reported less depression as a result of the therapy. However, it is important to note that $79 \%$ of the participants' reason for joining the study is because of a conflict between their religious belief and sexual identity. Moreover, 93\% of the participants also report that religion is important to them. The participants also claimed that they want to function well as a heterosexual by having a heterosexual partner. The elaboration above should be put into consideration when talking about the effectiveness of conversion therapy.

Another study [20] claimed that conversion therapy is effective and have only slight harmful effects. Their study was conducted on 125 men with strong religious belief and unwanted same-sex attraction. Participants claimed to have shifts in their sexual attraction, sexual identity, and sexual behavior. Furthermore, this study also claimed to have large statistical effects sizes, moderate to high decreases in suicidality, depression, substance abuse, and increases in social functioning and self-esteem. The study concluded that some degree of change is possible from conversion therapy for religious clients with unwanted same-sex attraction. Similar to Spitzer's, participants underwent the therapy for religious reason $(64 \%)$ and maintaining existing marriage (12\%),

Cognitive dissonance theory can be used in explaining the effect of conversion therapy in both Spitzer's and Santero's study. Cognitive dissonance is a concept introduced by Festinger [21], where an individual is motivated to confirm and convince oneself about their own decision, by modifying one's interpretation of a result. In conversion therapy, an individual spends their time to alter their sexual identity and accept society expectations for a change. This condition encourages them to discover its benefits by going through normal lifestyle of a heterosexual. In undergoing heterosexual lifestyle, especially through maintaining their heterosexual partner, marital status and family, they confirm their own beliefs on how the therapy is beneficial, even though the individual does not feel any significant change in their sexual identity. Those who live this way are very likely to experience low selfesteem, depression, anxiety, and even feeling suicidal $[22,23]$.

\subsection{The Implication of Conversion Therapy}

There are various reasons as to why individuals undergo conversion therapy. In general, LGBT individuals experience a lot of stress due to being in the minority, thus suffering from stereotypes and discrimination from the society [24]. There are also individuals who are internally motivated to change their sexual identity [25]. Regardless of external or internal motivation, LGBT individuals who seek help to alter their sexual orientation through conversion therapy are at risk of the negative consequences that may occur when the therapy fails.

Conversion therapy result in several consequences, such as spiritual and emotional crisis. This especially happens to homosexual individuals because they internalize, hence believe that homosexual is something wrong. Individuals who undergo therapy but fail to alter their sexual orientation may feel like a failure, which results in self-hatred, shame, depression, also sexual dysfunction. Exclusion of family and society is another example of consequences [22].

In relation to undergoing conversion therapy, a man mentioned that he was forced to undergo the therapy when he was 14 years old [26]. This was initiated by his school counselor when the school found out his sexual orientation. As a part of the therapy, he was told to read holy bible for one whole year. In addition, he was also taught that homosexuality is a sin, also its relation to diseases, mental disorders, and unhappiness in life. He stated that the therapy damaged his self-confidence, and he found it hard to socialize and speak in front of many people. Besides that, the therapy also instills guilt of his sexual orientation.

Reference [27] studied about mental health and selfadjustment among teenagers who are pushed by their parents to undergo conversion therapy. The study shows being forced by parents to change sexual orientation during adolescence is associated with low indicator in mental health and self-adjustment later in young adulthood. Negative association appears stronger among those who experience parents' effort to alter their sexual orientation, followed by the effort to bring them to therapist or religious leaders in teenage years. Conversion therapy among teenagers is associated with several functions related to self-care, well-being, and self-adjustment. Those teenagers who undergo 
conversion therapy are more associated with depression and suicide attempts, low life satisfaction, low social support, and low socioeconomic status [27].

Being forced into conversion therapy results in negative consequences. Additionally, among those who voluntarily seek and participate in conversion therapy, these consequences occur not only during therapy, but also after. Another study [11] found that after counseling, gay men still identified themselves as gay. Furthermore, these men also find it hard to accept their identity, even having suicidal thoughts. They hate and reject themselves, have low self-esteem, suffer depression, and also are unable to understand and accept their identity as gay.

On the other side, few studies that claimed to be successful in changing sexual orientation stated that most participants reported less depression, suicidality, and substance abuse as a result of the therapy $[19,20]$. In addition, participants [20] stated that they experienced a marked increase in social functioning and self-esteem, and no harming results from the therapy. It can be said that religiosity is a defining factor in conversion therapy, where most of the successful conversion claims come from strongly religious participants.

Study [25] collected data on homosexual men who were willing to undergo conversion therapy because of their unwanted same-sex sexual feelings and behavior. The study gathered 117 people who had undergone conversion therapy for the past 6 months, and had some past or current form of same-sex attraction. Based on the results of the study, it was found that married men felt a greater decrease in sexual feelings and behavior compared to singles. It is likely because married men have greater stake in relation to their spouse and child. The heterosexual lifestyle of married men can also be a form of sublimation of their homosexual drive.

Interestingly, men who have same-sex attraction but does not identify themselves as homosexuals based on Kinsey scale (e.g. predominantly heterosexual, equally heterosexual and homosexual), experiences less change in their sexual feelings and behavior toward men. The more they identify their sexual identity as heterosexual, the less motivated they are to change their same-sex attraction compared to those who feel conflicted with their sexual identity [25].

\subsection{Ethical Issues of Conversion Therapy}

In addition to some of the conversion therapy consequences, there are also reports about its ethical issues [23]. In a case of a school counselor who knows the student's homosexual orientation, the school counselor reveals the information to the school institution instead of maintaining confidentiality. This alone violates the client's confidentiality and even results in dropping out of the student. The client is also pressured and threatened to submit to the counselor's authority. When conversion therapy does not succeed, most of the therapists fail to refer the client to a more affirming therapist. They even continue to recommend conversion therapy to everyone [23].

Besides that, conversion therapy often emphasizes more on client's motivation instead of therapist's capability to perform the given intervention. This leads to the clients to believe that when the therapy fails, it is due to their lack of motivation. Clients may blame themselves and question their motivation, which then worsen their depression and anxiety. More often than not, this thought leads the LGBT individuals to end their lives. Other cases reported that the clients were asked to date and marry the opposite sex. Most of the clients are able to maintain their marriage after years and even have children, however they are aware that there is no change in their sexual orientation. As a result, the family suffers from negative consequences [23].

While contrary to the others, this research argued that clients with unwanted same-sex attraction have the rights to seek help from professionals regarding their sexual orientation. Clients self-request for conversion therapy should be respected. The therapy itself could benefit them in decreasing depression, self-harm, suicidality, and substance abuse, especially in strongly religious clients [20]. Nevertheless, American Psychiatric Association has stated that conversion therapy is a harmful therapy for the client and is not supported by strong scientific proof or data [28]. Furthermore, The National Association of Social Workers [29] has also released a statement that conversion therapy cannot and will not change one's sexual orientation. Thus, it is not commendable for social workers to practice conversion therapy.

\subsection{Solutions to Conversion Therapy}

Based on the discussion, conversion therapy is not effective to change one's sexual identity and sexual orientation, especially when the request for conversion is forced by others. Homosexuality is not a disease, hence a cure is unnecessary. Even so, apart from being ineffective in altering sexual orientation, conversion therapy can offer another help through sense of connectedness with other people and sense of acceptance during therapy [10].

In most cases, LGBT individuals cannot accept their sexual orientation, hence seeking therapist and asking to be cured. Being pressured by their own family and society may underlie this situation, which can cause the internalization of homophobia in the individuals. As mentioned in [10], the main reason why an individual undergo conversion therapy is because of religious belief, as well as the willingness to maintain 
heterosexual lifestyle, especially among those who are married and have children. Moreover, in Indonesian context where religion is a strongly held value, people who tend to be religious may label themselves as a sinner because of their sexual orientation. Therefore, homosexuals in Indonesia may feel the urge to undergo a conversion therapy to diminish their guilt.

The alternatives that can be offered to LGBT individuals are affirmative psychotherapy and integrative solution therapy. Affirmative psychotherapy is a form of psychotherapy intended for non-heterosexuals which focuses on client's self-acceptance of their sexual orientation. This psychotherapy does not intend to make them become heterosexuals or to eliminate their sexual attraction or behavior towards same-sex individuals. American Psychological Association (APA) has also provided guidance and materials for affirmative psychotherapy. Literatures define affirmative psychology more as attitudes shown by therapists than a specific technique [30].

In [3], affirmative psychotherapy is defined with four main themes; first, eliminating anti-LGBT attitude and showing affirmation; second, enriching oneself with the right knowledge about LGBT various experiences; third, adjusting the integration between the right knowledge and therapeutic actions; lastly, overcoming challenges in inequality. Affirmative and client-centered intervention allows the client to get to a conclusion in particular and also helps them to develop positive coping strategies in facing society [9].

The other alternative therapy is integrative solution therapy. It is a form of therapy which attempts to appreciate and value client's whole identity aspect and give them unconditional positive regard. In this therapy, the therapist supports the client to see how society sometimes degrade and oppress the minority. Its purpose is to help client realize and accept their pain and loss, neutralize their shame, and strengthen the client to be able to live for themselves, not for social institution that forces them to submit to its standards [22].

Sharing the same purpose of counseling and therapy in general, counselor's intention is to help the client to realize and accept their current condition, also giving insight about their situation, independent from the counselor's own value. As a result, if an individual is forced by others to undergo conversion therapy, it is important for the counselor to dig about the client's view on their sexual orientation. If the client is bothered by their sexual orientation, the client may seek professional help, however the urge has to come from themselves [22].

Before determining any kind of intervention, it is better to assess client's spectrum of homosexuality, their view on sexuality, and their values more thouroughly. As an example, in clients who are predominantly heterosexual and wanting conversion therapy because of their religious belief, therapist can help them to at least practice abstinence from same-sex sexual behaviors and lifestyles. As in clients who are exclusively homosexual, therapist should help clients to have a better self-acceptance through counseling. Client should have an understanding that any therapy does not "cure" sexual attraction but it could change sexual behavior, for example by practicing celibacy or avoiding sexual activities with the same-sex individuals. However, therapists need to be aware that this can reduce other aspects of the client's life, such as lack of emotionality. A therapist is obliged to explain all of these considerations to the client as well. The therapy should also be unbiased, such as encouraging the individual to take a decision in particular, for it could be harmful and unethical [31].

\section{CONCLUSION}

This article aims to discuss the effectiveness and ethical issues of conversion therapy in altering one's sexual orientation. Based on the discussion and evidence stated above, the researchers conclude that conversion therapy is not effective in changing one's sexual identity and sexual orientation, especially if the request came from others. It is important to understand that the occurrence of conversion therapy is caused by a rising conflict between individual's cultural belief and their attraction to same-sex individuals. Thus, as long as society remains urging and forcing mindset, religious beliefs, and policies that discriminate sexual minority, conversion therapy will never cease to exist, despite its ineffectiveness and scientific factors [8].

Nevertheless, it does not mean that therapist should entirely decline client's own request to change their sexual orientation. Deeper understanding about one's strongly held value, their view of sexuality, as well as their sexual orientation continuum can lead to more effective treatments. 'Conversion therapy' may still be done to bisexual or predominantly heterosexual individuals who desire to change their sexual orientation, by changing their lifestyle and same-sex sexual behavior. However, therapists need to explain that sexual attraction cannot be changed, but sexual behavior can be adjusted to values that are considered important for the client. Therapist and the client need to discuss and carefully consider the various consequences that may be experienced by the client in the future.

This study contributes to give better understanding of the effectiveness and ethical issues surrounding society's request for conversion therapy for homosexuals, especially among Indonesians who still find it hard to accept the existence of other sexual orientation. This study emphasizes on the importance of scientific evidence in claiming 'cure' to alter one's sexual 
orientation. As a clinician, an ethical way dealing with LGBT clients is to gain a thorough understanding about client's value and view of their sexual orientation. Intervention should focus more on addressing challenges and difficulties faced by sexual minorities through delivering psychoeducation, also to help them find resources to face stereotypes and discriminative behaviors from society [31].

\section{REFERENCES}

[1] G. Butler, Exorcisms are being used as gay conversion therapy in Indonesia, 2018. Available online:

https://www.vice.com/en_au/article/3k95x5/exorci sms-are-being-used-as-gay-conversion-therapy-inindonesia

[2] CNN, BKKBN sebut LGBT musuh pembangunan, 2019. Available online: https://www.cnnindonesia.com/nasional/20190603 202457-20-400777/bkkbn-sebut-lgbt-musuhpembangunan.

[3] B. Moradi and S. L. Budge, "Engaging in LGBQ+ affirmative psychotherapies with all clients: Defining themes and practices,".Journal of Clinical Psychology, pp. 1-15, 2018.

[4] R. Ridwan and J. Wu, "'Being young and LGBT, what could be worse?' Analysis of youth LGBT activism in Indonesia: challenges and ways forward," Gender \& Development, vol. 26, pp. 121-138, 2018.

[5] A. J. Chrisler, "Understanding parents reactions to coming out as lesbian, gay, or bisexual: A theoritical framework," Journal of Family Theory and Review, vol. 9, pp. 165-181, 2017.

[6] A. C. Kinsey, W. B. Pomeroy and C. E. Martin, Sexual Behavior in the Human Male. Oxford, England: Saunders, 1948.

[7] J. Drescher, "Out of DSM: Depathologizing homosexuality," Behavioral Science, vol.5, pp. $565-575,2015$

[8] A. Flentje, N. C. Heck, and B. N. Cochran, "Sexual reorientation therapy interventions: Perspectives of ex-ex-gay individuals,". Journal of Gay and Lesbian Mental Health, vol. 17, pp. 256-277, 2013.

[9] American Psychological Association, Task Force on the Appropriate Therapeutic Response to Sexual Orientation, Report of the task force on the appropriate therapeutic response to sexual orientation. Washington, DC, USA, 2009.
Available online: https://www.apa.org/pi/lgbt/resources/therapeuticresponse.pdf

[10] A. Flentje, N. C. Heck, and B. N. Cochran, "Experiences of ex-ex-gay individuals in sexual reorientation therapy: Reasons for seeking treatment, perceived helpfulness and harmfulness of treatment, and post-treatment identification," Journal of Homosexuality, vol. 61, pp. 1242-1268, 2014.

[11] J. V. Zyl, K. Nel and S. Govender, "Reparative sexual orientation therapy effects on gay sexual identities," Journal of Psychology in Africa, vol. 2, 191-197, 2017.

[12] American Psychiatric Association, Diagnostic and Statistical Manual of Mental Disorders, 2nd ed., seventh printing; American Psychiatric Press: Washington, DC, USA, 1974

[13] American Psychiatric Association. Diagnostic and Statistical Manual of Mental Disorders, 5th ed.; American Psychiatric Press: Washington, DC, USA, 2013.

[14] J. S. Greenberg, C. E. Bruess, and S. B. Oswalt, Exploring the Dimensions of Human Sexuality, 6th ed. USA: Jones \& Bartlett Publishers, 2016.

[15] "Pink therapy," D. Davies and C. Neal, Eds. Philadelphia, PA: Open University Press, 2003.

[16] W. J. Jenkins, “Can Anyone Tell Me Why I'm Gay? What Research Suggests Regarding The Origins of Sexual Orientation," North American Journal of Psychology, vol. 12, pp. 279-296, 2010.

[17] J. Ponseti, H. A. Bosinski., S. Wolff, M. Peller, O. Jansen, H. M. Mehdorn, C. Büchel,, and H. R. Siebner, "A functional endophenotype for sexual orientation in humans," Neuroimage, 2006, vol. 33, pp. 825-33.

[18] S. H. Hu, N. Wei, Q. D. Wang, L. Q. Yan, E. Q. Wei, M. M., Zhang, J. B. Hu, M. I. Huang, W. H. Zhou, dan $\mathrm{Y} . \mathrm{Xu}$, "Patterns of brain activation during visually evoked sexual arousal differ between homosexual and heterosexual men,' American Journal of Neuroradiology, 2008, vol. 29.

[19] R. L. Spitzer, "Can some gay men and lesbians change their sexual orientation? 200 participants reporting a change from homosexual to heterosexual orientation," Archives of Sexual Behavior, vol. 32, pp. 403-417, 2003.

[20] P. L. Santero, N. E., Whitehead and D. Ballesteros, "Effects of therapy on religious men who have 
unwanted same-sex attraction," The Linacre Quarterly, pp. 1-17, 2018.

[21] L. Festinger, A theory of Cognitive Dissonance. Palo Alto, CA: Stanford University Press, 1957.

[22] J. Horner, "Undoing the damage: Working with LGBT clients in post-conversion therapy," Columbia Social Work Review, vol. 1, pp. 8-16. 2010.

[23] J. Drescher, "Can sexual orientation be changed?," Journal of Gay \& Lesbian Mental Health, vol. 19, pp. 84-93, 2015.

[24] N. C. Heck, A. Flentje, and B. N. Cochran, "Intake interviewing with lesbian, gay, bisexual, and transgender clients: Starting from a place of affirmation", Journal of Contemporer Psychotherapy, 2013, vol. 43, pp. 23-32.

[25] E. Y. Karten \& J. C. Wade, "Sexual orientation change efforts in men: A client perspectives", Journal of Men's Studies, 2010, vol. 18, pp. 84102.

[26] J. Beer, "Testimony on sexual orientation change efforts," Journal of Gay \& Lesbian Mental Health, vol. 19, pp. 94-95, 2015.
[27] C. Ryan, R. B. Toomey, R. M. Diaz, and S. T. Russell, "Parent-initiated sexual orientation change efforts with LGBT adolescents: Implications for young adult mental health and adjustment," Journal of Homosexuality, 2018.

[28] American Psychiatric Association, COPP position statement on therapies focused on attempts to change sexual orientation (reparative or conversion therapies), 2006. Available online: http://www.psych.org/psych_pract/copptherapyadd endum83100.cfm

[29] National Association of Social Workers, Social Work Speaks. Washington, DC, USA, 2006.

[30] K. L. M. Hinrichs and W. Donaldson, "Recommendations for use of affirmative psychotherapy with LGBT older adults," Journal of Clinical Psycholog: In Session, vol 73, pp. 945953, 2017

[31] K. Ranade and S. Chakravarty, "Coming out of the comfort zone: Challenging heteronormativity through affirmative counselling practice with lesbian and gay clients," in Ethical Issues in Counselling and Psychotherapy Practice, P. Bhola and A. Raguram, Eds. Singapore: Springer, 2016, p. 141-154. 


\begin{tabular}{|c|c|c|c|c|c|c|}
\hline 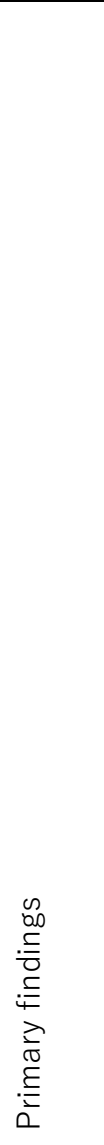 & 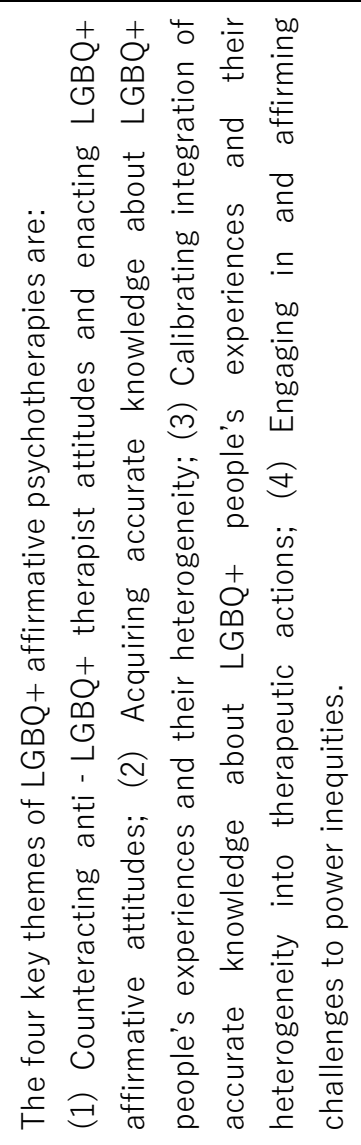 & 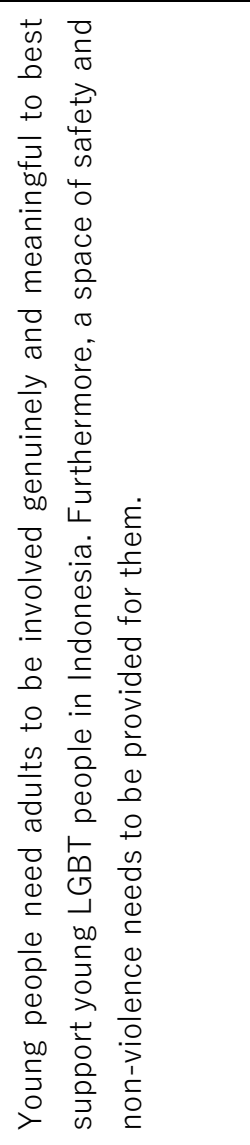 & 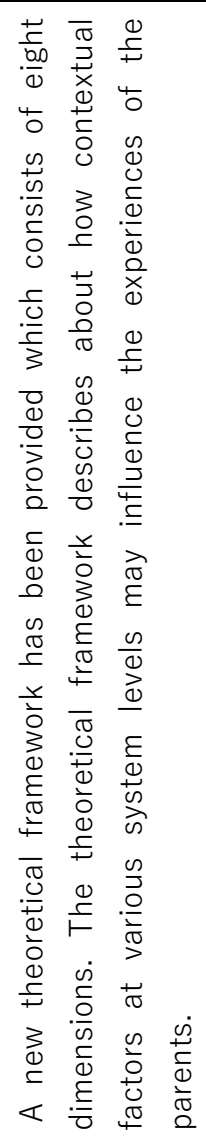 & 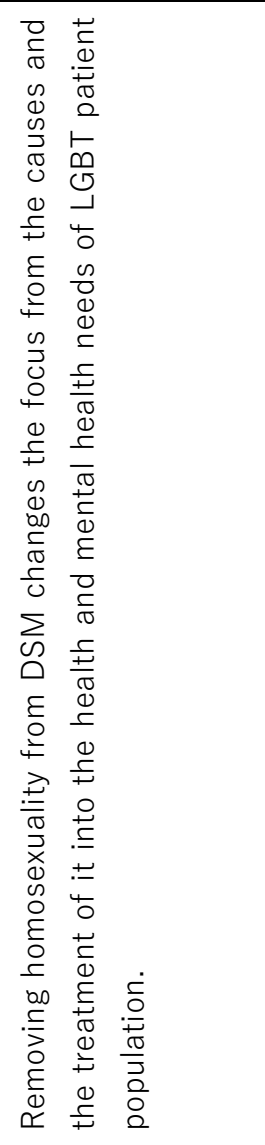 & 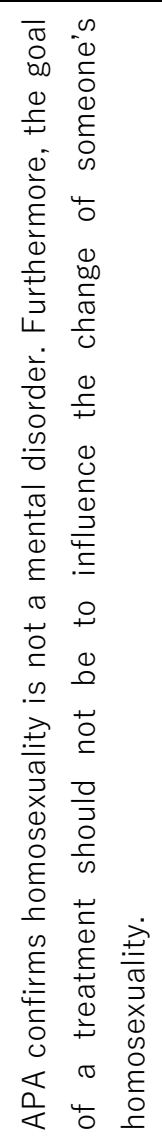 & 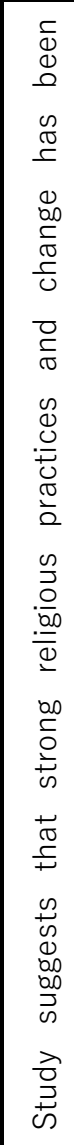 \\
\hline & 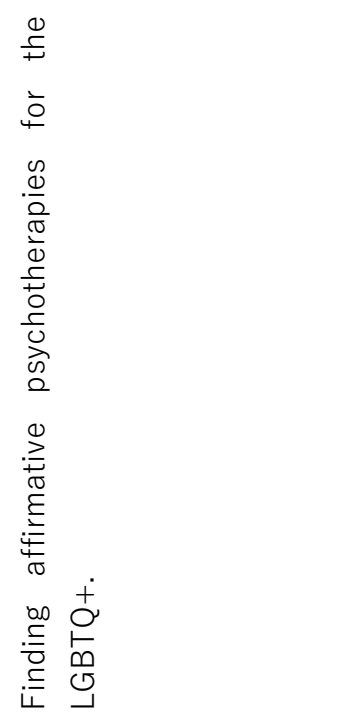 & 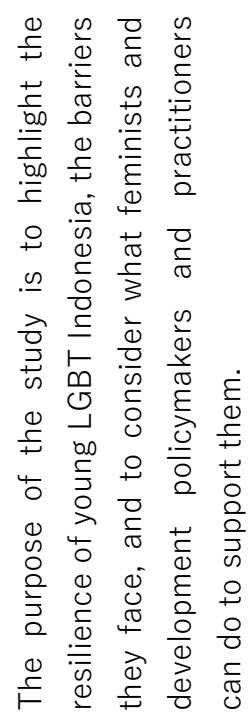 & 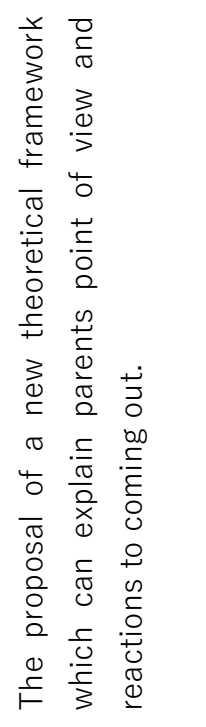 & 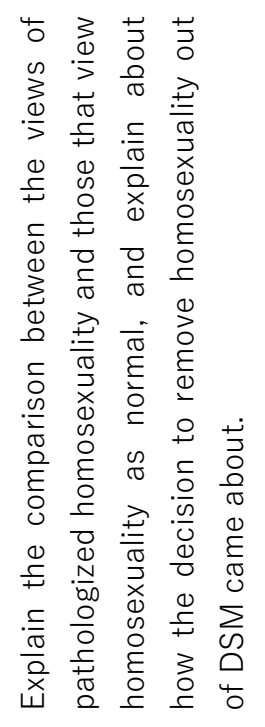 & 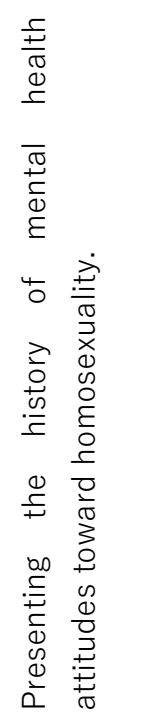 & 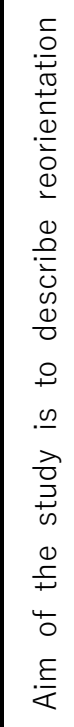 \\
\hline 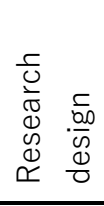 & 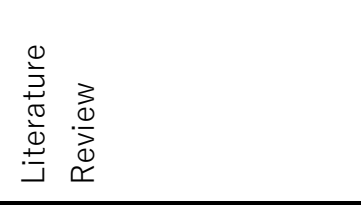 & 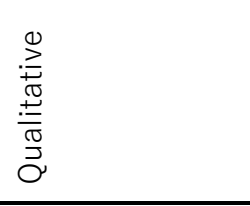 & 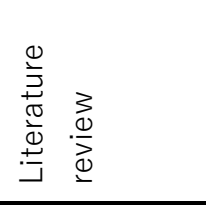 & 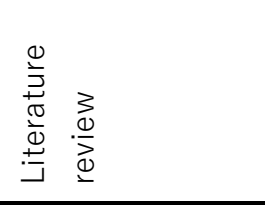 & 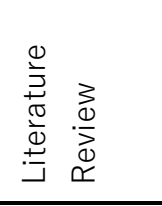 & 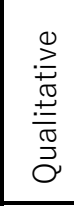 \\
\hline 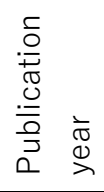 & $\begin{array}{l}\infty \\
\stackrel{\sim}{\sim}\end{array}$ & $\begin{array}{l}\infty \\
\stackrel{\sim}{\sim} \\
\sim\end{array}$ & 穴 & $\stackrel{\stackrel{\sim}{\prime}}{\stackrel{\sim}{\sim}}$ & 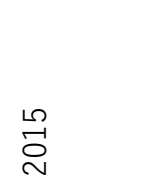 & $\stackrel{m}{\stackrel{n}{\sim}}$ \\
\hline \begin{tabular}{l}
$\frac{0}{0}$ \\
$\overline{0}$ \\
$\frac{1}{ \pm}$ \\
\multirow{2}{*}{}
\end{tabular} & $\begin{array}{ll}\overline{\bar{\sigma}} & 0 \\
\bar{\sigma} & \infty \\
\overline{0} & \overline{0} \\
\bar{\nu} & \bar{\partial}\end{array}$ & $\begin{array}{l}\sum_{\infty}^{5} \\
\infty \\
\frac{1}{\pi} \\
\frac{3}{0} \\
\frac{0}{\alpha} \\
\frac{0}{\alpha}\end{array}$ & 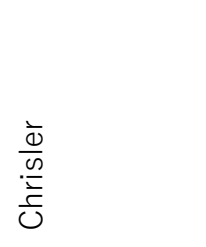 & 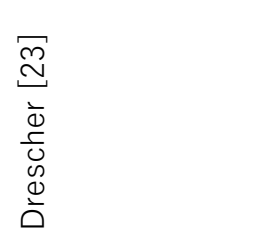 & 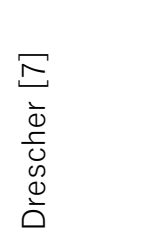 & 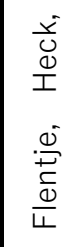 \\
\hline
\end{tabular}




\begin{tabular}{|c|c|c|c|c|c|c|}
\hline 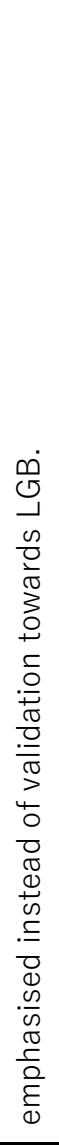 & 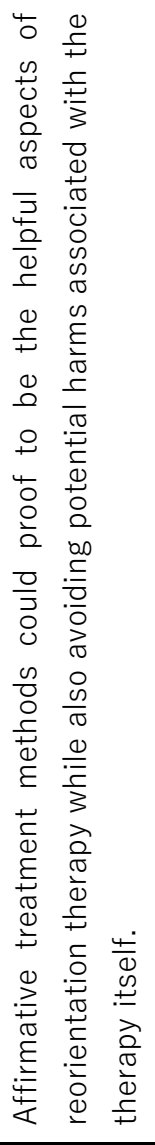 & 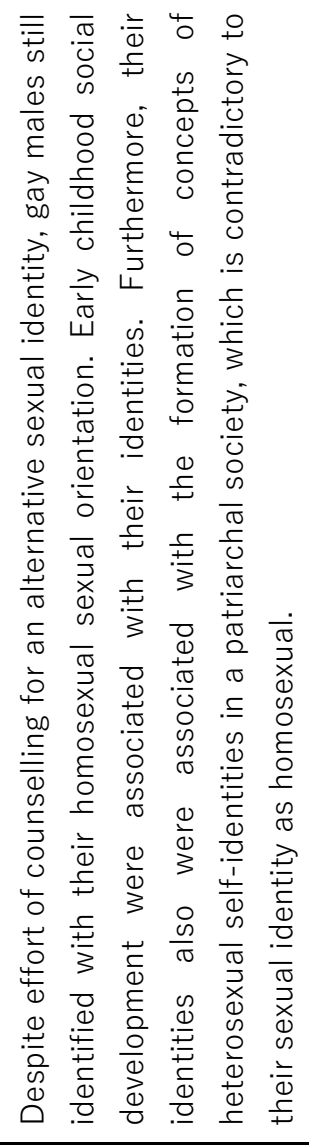 & 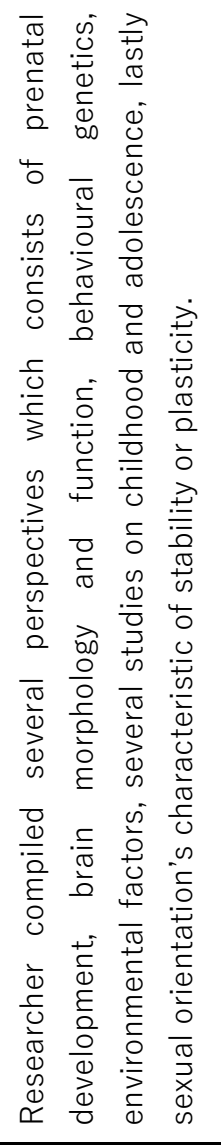 & 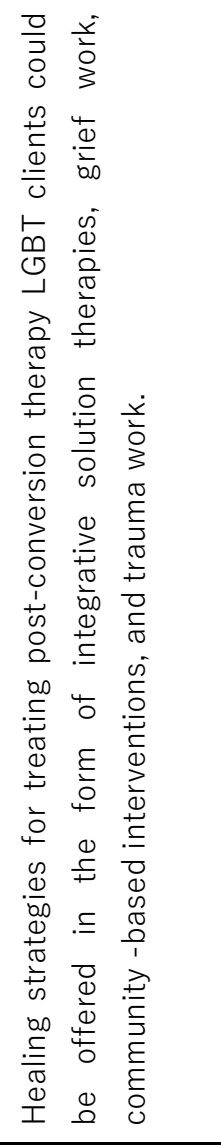 & 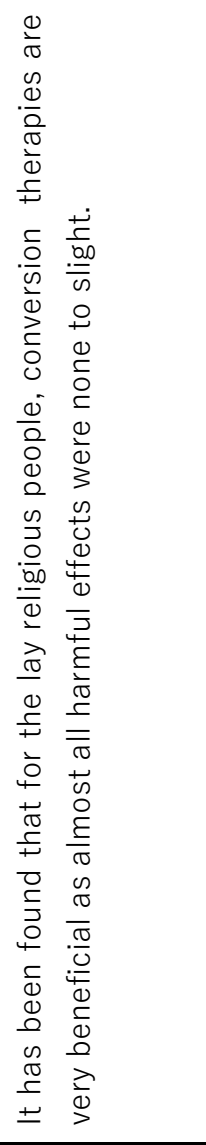 & 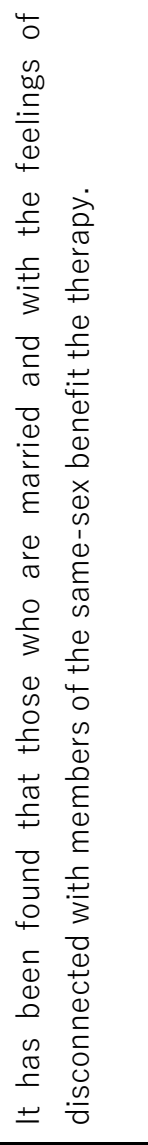 \\
\hline 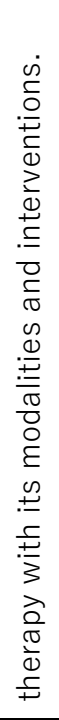 & 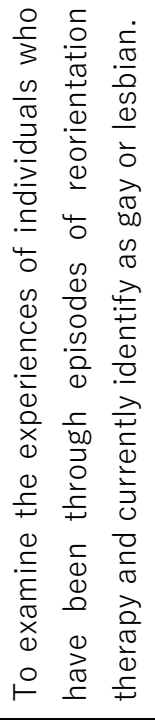 & 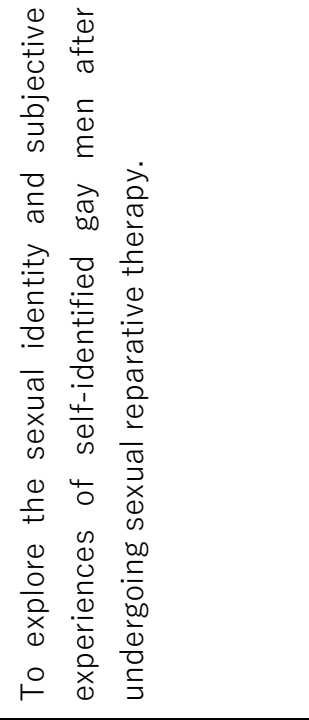 & 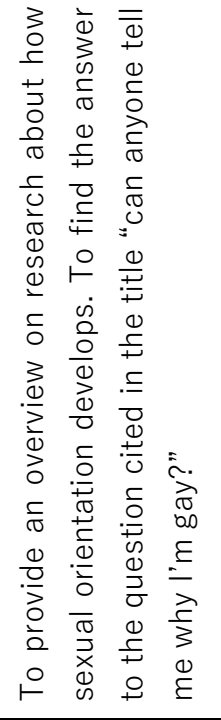 & 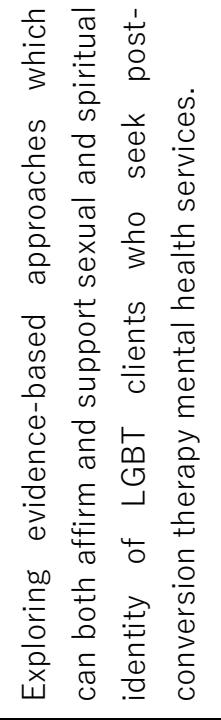 & 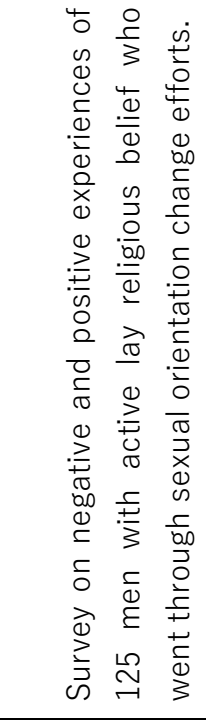 & 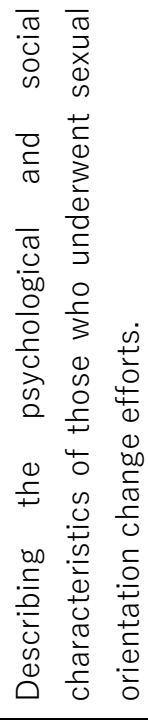 \\
\hline & 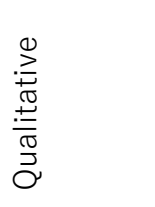 & 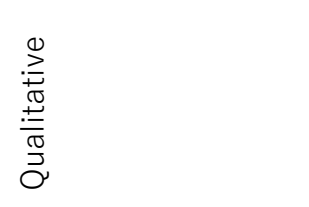 & 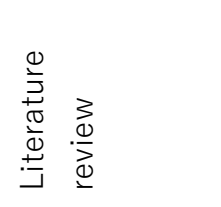 & 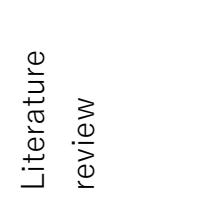 & 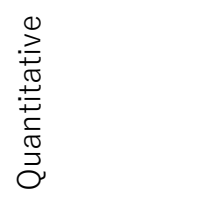 & 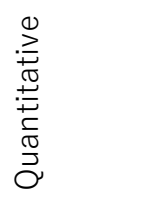 \\
\hline & $\underset{\sim}{\vec{\sim}}$ & $\overrightarrow{\stackrel{\sim}{v}}$ & $\begin{array}{l}\stackrel{\circ}{\sim} \\
\text { مे }\end{array}$ & 总 & $\begin{array}{l}\infty \\
\stackrel{\sim}{\sim} \\
\sim\end{array}$ & $\begin{array}{l}\stackrel{0}{0} \\
\stackrel{\sim}{\sim}\end{array}$ \\
\hline $\begin{array}{l}\frac{C}{\sigma} \\
\frac{0}{2} \\
\text { U } \\
0 \\
0 \\
\infty\end{array}$ & 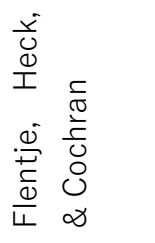 & 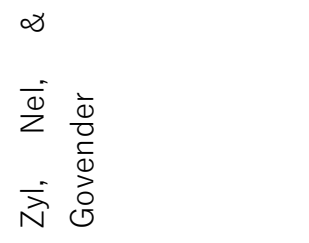 & 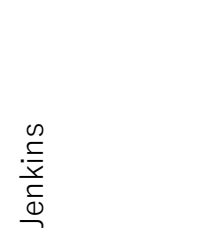 & $\begin{array}{l}\bar{\Phi} \\
\stackrel{ \pm}{ \pm} \\
\text { 온 }\end{array}$ & 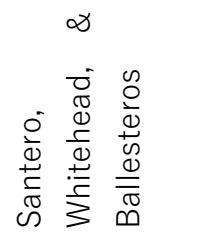 & 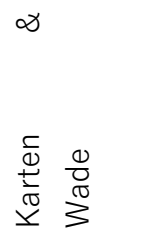 \\
\hline
\end{tabular}




\begin{tabular}{|c|c|c|}
\hline 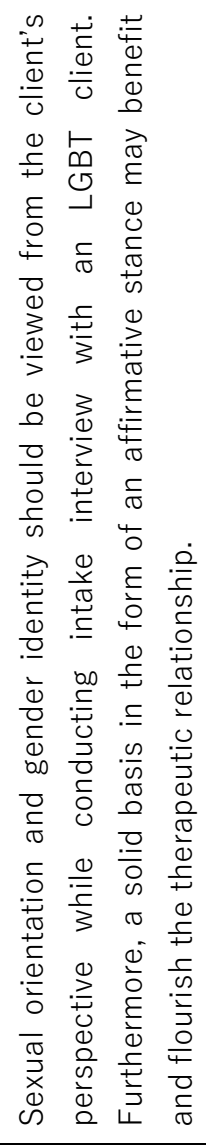 & 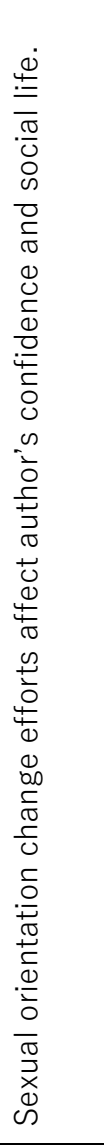 & 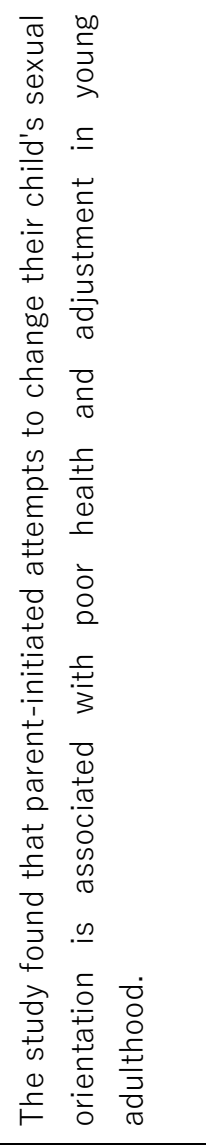 \\
\hline 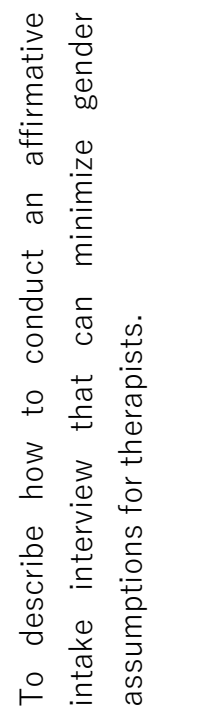 & 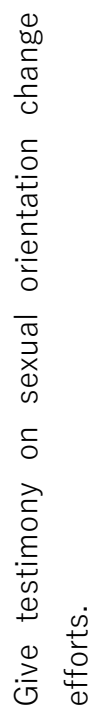 & 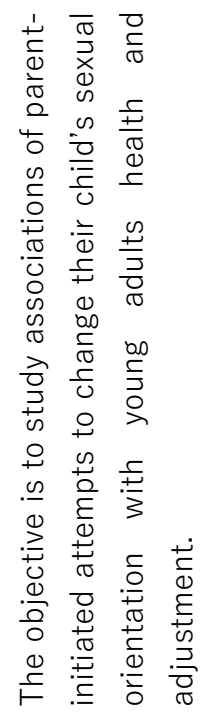 \\
\hline 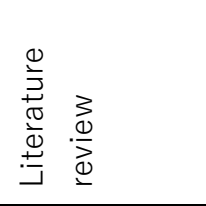 & 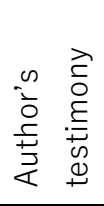 & 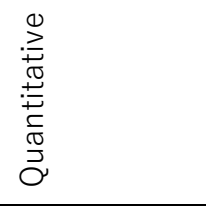 \\
\hline$\stackrel{m}{\stackrel{m}{\sim}}$ & $\stackrel{\stackrel{L}{\sim}}{\stackrel{\sim}{\sim}}$ & $\stackrel{\infty}{\stackrel{\infty}{\sim}}$ \\
\hline 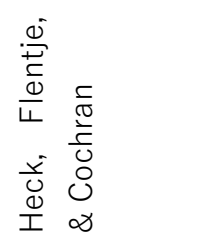 & $\begin{array}{l}\bar{\Phi} \\
\Phi \\
\infty\end{array}$ & 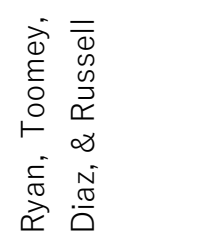 \\
\hline
\end{tabular}

